\title{
Educational Change and Inclusion: Lessons from A Collaborative Action Research
}

\author{
TM Makoelle \\ University of Johannesburg \\ Email: tmakoelle@uj.ac.za

\section{MP Van Der Merwe}

Unıversity of Johannesburg

Email: martynvdm@uj.ac.za

\section{Doi:10.5901/mjss.2014.v5n14p169}

\begin{abstract}
There is a global reform process to change education towards inclusive education. This process is sometimes complicated because the process of developing practices of inclusion often involves a change in teacher beliefs, attitudes and practices. This paper therefore attempts to draw lessons from collaborative action research and teacher collaboration in implementing change towards inclusive settings in a selected secondary school in the Free State Province of South Africa. A literature review was undertaken to build a conceptual framework and an analysis of the action research process done using group interpretative and inductive analysis frameworks. The study has found that teacher driven change and teacher participation and collaboration were pivotal in developing and implementing inclusive practices.
\end{abstract}

Keywords: Community of enquiry, Education Change, Collaborative Action Research, Inclusive practice, Teacher collaboration

\section{Introduction}

In 1994 the dawn of the new democratic dispensation saw many changes in the education system of South Africa. Among those changes, the White Paper 6 (DoE 2001) became the roadmap to implement inclusive education (Makoelle 2012). This was aligned with the general transformation process to change South Africa into an inclusive, equitable, fair and just society. The process of change in the education sector was driven alongside political changes and teachers within the education sector were to act as agents of change wherein they were at the delivery or implementation layer of these educational changes. One of the processes of change besides curriculum implementation that teachers had to manage was changing education from its exclusive nature to a more inclusive form. This process presented many challenges of which some are still currently visible. In the White Paper 6 it was made clear that schools were to, as far as possible; accommodate learners regardless of their race, gender, socio-economic status and most importantly disability (Makoelle 2012). Current studies show that teachers experienced challenges to suddenly accommodate all learners since their training did not necessarily include this approach, and in many cases work comfortably where learners are simply categorised according to ability and disability. This has prompted asking the following questions:

How could change towards inclusive education be appropriately implemented?

Which forms of change strategies could be appropriate in implementing inclusive education within the South African context?

To answer these questions, the paper conceptualises change, discusses some commonly used strategies in implementing inclusion and conclude by drawing some lessons from the collaborative action research adopted in this study as a change strategy.

\section{Conceptualising Change}

The process of bringing about change is complex and conceptualised differently by different people. Inclusive education is the process whereby the school responds to the needs of all learners regardless of their background (Ainscow 1999). Learners should be accommodated by the school in all aspects of teaching and learning. They should not be expected to adapt to the school; rather, the school should adapt to the learners by ensuring that all their needs are met (DoE 2005). The purpose of inclusive education seems to be mutual to that of educational change because the ultimate aim of 
educational change (reform) is to benefit all learners (Fullan 1999). Therefore implementing inclusive education requires some form of change process.

Change is often regarded as a complex and difficult process to initiate and implement. Schools are places characterised by a high degree of diversity, and those individuals at school relate to one another according to the school's protocol of authority, responsibility and reflect notions of power. Furthermore, notions of equity and equality cannot be divorced from the change process. Change is influenced by a number of factors at the school. Increased teacher responsibility and administrative loads are a serious hindrance to the realisation of change in schools. Fullan (2001) postulates that a great deal is expected of teachers, even though they receive very little support from the education authorities and parents. Teacher's experience what could be referred to as "low morale", the phenomenon associated with low motivation among teachers. Schools are often highly politicised, which only serves to create a barrier to the effective initiation and implementation of change (Fullan 2001). Change does not occur in a vacuum, but takes place in a particular way and according to certain patterns. Change is known to be influenced by factors such as a need which becomes a priority of the school community; clear sets of objectives and goals which the school wants to achieve.

On the other hand, change can be evaluated and its quality can be assessed. Some practical implications are found to be associated with change, for example the availability of resources and time. It is important that schools guard against politically ambitious change programmes (Fullan 2001). There are instances where the tradition of leadership in countries such as South Africa results in principals and education officials often resorting to autocratic means to impose changes on teachers (Engelbrecht \& Green 2001; Weber 2007). The system is characterised by a suppressive political ideology. In such circumstances, change is mostly driven by a political agenda and could perpetuate exclusion.

\subsection{Some approaches to education change}

There are many approaches to change; for example, Fullan (1999: 39) distinguishes between the complexity and the evolutionary approach. The complexity approach denotes that change is an interactive rather than a linear process. The link between cause and effect does not exist and change operates in a continuum ranging from the scale of stability to instability. The evolutionary approach, on the other hand, refers to how humans evolve over time in relation to their interaction and cooperative behaviour.

The school is a place where activities take place according to planned routines and timetabling; however, when policies have to be implemented or changes effected, the school is an unpredictable environment. It is for this reason that the complexity approach becomes important for the process of educational change.

Change is dependent on the capacity of teachers to create knowledge with the purpose of learning new ideas. Change takes place in what Fullan (1999) calls a social collaboration context. The process of social collaboration occurs within the framework of a collaboration culture; that is, the culture where all members of the school community work as a team to achieve a common purpose. Social collaboration respects diversity while building trust among the participants. It may instil anxiety among the participants but also absorb it.

Knowledge is created through interactive engagement and connections. Change is an open system, subject to the contributions of the collaborating members (Fullan 1999). The spiritual, political and intellectual aspects are significant during the process of change, which could expand beyond the periphery of the school into the outside world by making connections, which is often referred to as "networking" (Ainscow et al. 2006).

The complexity approach is described by using the analogy of a systems approach to define the school's process of change as a system. Educational change is a complex system, and change is dynamic and metabletic in nature. The dynamic nature of teaching also makes change even more complex, because each class of learners represents a unique educational context drawn from a diverse knowledge, cultural and socio-economic background. Educational change can only materialise as a collective rather than as an individual endeavour (Hoban 2002). To think about change, Hoban argues, teachers have to apply systems thinking, which is seeing the interrelationship between the whole and its parts. Systems thinking is in contrast with the notion of a piecemeal approach to the implementation of change, because, when it is applied, reality could be so complex and dynamic that it refutes the linear cause-effect model of educational change.

\subsection{Role of teachers in a change process}

According to Hoban (2002), for teachers to understand change, they should establish a learning community (a group of persons in pursuit of a common learning objective), which could be very helpful in that teachers may draw strategies together and challenge their beliefs to make change easier. Such a community is based on teacher cooperation and team work. Teachers should be willing to share power and authority, be independent to some extent, and be motivated by the 
purpose of learning together. The learning community is a collective focused on building the capacity of teachers to reflect on their teaching practices; communicate effectively among themselves and provide the necessary inputs for the process of change.

The notion of how teachers change is a complex issue. Similarly, the way teachers conceptualise the notion of changing from a traditional to an inclusive teaching method is a difficult and on-going process. It is significant for teachers to take the opportunity to reflect on the proposal for change by reviewing their values and beliefs and the manner in which these values affect their daily work. Teachers should allow themselves to think on their own about change rather than having change imposed on them. A platform could be created for teachers to discuss and reflect on how change will be planned, implemented, monitored and controlled (Mittler 2000).

The notion of change is referred to as a process encompassing concepts such as beliefs, attitudes, knowledge, understanding, self-awareness and teaching practice (Richards, Gallo \& Ranandya 2001). Educational change has to take into consideration teacher beliefs and attitudes which necessarily influence personal vision and mission, if it is to be successful. Recognising teacher beliefs elevates their motivation because they will see themselves as valuable members of the learning community (Goodson 2003). Teacher beliefs are important because, together with their context, they shape how they will relate to the change process. The latter process becomes more effective when a bottom-up rather than a top-down approach is used. Change also works well when not imposed (Richards et al. 2001). However, often education departments implement politically driven systemic changes, ignoring what works and is best for the situation. Educational change has to involve all teachers for it to be accomplished (Fullan 2001).

Teachers have to be supported in their quest for transformation and change. They have to be motivated in order for them to be committed to the process of change. Haney et al. (2002) conducted a research project on teacher motivation and their will to implement change. They discovered that any reform in education will succeed if it takes the beliefs of teachers into consideration. The research indicated that the belief teachers have about themselves influences how they conceptualise change; for example, if teachers hold the belief that they are capable in their work, this has a profound influence on their motivation and consequently on their self-efficacy, raising their willingness to implement change. The theory of motivation as a system depicts how the teacher's will to implement change is influenced by his/her self-efficacy and situational context (Boekaerts \& Cascallar 2006). This implies that, if the teacher regards himself/herself as competent, the school environment is conducive to change, adequate support is given, and the teacher is motivated, chances are that change will be successfully implemented.

\subsection{School environment, leadership, collaboration and change}

Change cannot take place at the school if the leadership of the school does not support it. Although change is one of the processes that occur at the school, it is often difficult to manage and it cannot be controlled easily (Fullan 2004). What is emphasised here is that the leadership of the school should understand change rather than try to control it. Fullan cautions against leaders imposing their own innovative ideas on teachers. Leaders have to inculcate respect for the opinions and ideas of others. Leaders should understand that change is not a smooth process, but that it is characterised by what Fullan calls an implementation dip, which is the time when an envisaged plan goes awry. It is the process attributable to resistance that could develop among teachers against the change process. Leaders have to note that addressing resistance has to include defining what resistance is, listening to those opposed to change, trying to find out why they resist change, trying to address their concerns, and incorporating their inputs into the broader change programme. Leadership should embark on what is called re-culturing, which is developing a culture in collaboration with teachers. This includes building a network of support, and maintaining good interpersonal relationships based on trust and respect between the leadership of the school and teachers. The teachers and the leadership should engage with one another in shaping and exchanging knowledge and ideas.

Engelbrecht and Green (2001) argue that change in the South African context is hampered by resistance from the teachers because of the oppression of and injustices meted out to teachers by the former apartheid education system. To implement change towards a more inclusive system, Engelbrecht and Green (2001:33) suggest that change should begin with the principal of the school, whose vision must encapsulate what is called an "inclusive tone"- a step in the development of an inclusive learning community. Unlike in the past, he/she should drift away from being autocratic to being democratic and allow participatory leadership and inclusive management. The school will change if the vision of the leadership creates an inclusive culture and climate. Such a culture transforms assumptions, beliefs, values, norms, relationships behaviour and practice. The inclusive culture could be accomplished through the collaboration and collegiality of teachers working together to achieve a common purpose.

The leadership of the school should create conditions for the following to take place: 
- Collaborative problem-solving - when teachers work together to solve a problem;

- Peer coaching - when teachers coach one another in their work;

- Co-teaching - when teachers teach the same class to assist one another;

- Facilitating cooperative learning - the teachers have to learn to plan and organise cooperative learning.

Most researchers believe that teachers implement change when they are fully involved in initiating, designing, and implementing it. Ainscow et al. (2006) indicate that they have worked with teachers collaboratively and embarked on an action research project which saw teachers become researchers in developing inclusive practices at their schools. Ainscow et al. (2006: 56) had the following to say about collaboration as a strategy to develop inclusive practices in schools:

Rather than handing practitioners a blueprint for action we sought to work collaboratively with them to explore how their context could be understood and what actions might be possible therein.

The process referred to as collaborative enquiry began with teachers and experts participating in a workshop to develop a common understanding about how the project should be run. The teachers and experts established a network which all teachers participated in as part of their development plan. Joint meetings involving both practitioners and researchers were held to engage with the evidence collected. Teachers were allowed to investigate their own practice as part of the school's agenda while researchers pursued their own research agenda; however, both worked collaboratively (Ainscow et al. 2011). Collaborative enquiry fosters mutual relationships between the researcher and teachers. Thus focuses on the significance of the agenda of both the researcher and the teachers. It is from the collected data and evidence that both parties will begin to map out their respective agendas to plan change and transformation. The collected data and evidence becomes the central core of discussions during the analysis and the interpretation processes. The discursive engagement is referred to as a group interpretive process as all participants are engaged as a collective in the process. The issue of different explanations and interpretations is addressed through dialogue, thus also dealing with the trustworthiness of the process.

Collaboration is often regarded as critical for action research and therefore crucial to the educational change process (Somekh 2006). In the process of collaboration, the process of triangulation becomes prominent as it allows participants to look at concepts from a multiplicity of perspectives. Various methods could be used in this process, including processes such as observations, interviews, statistics, and specimen teaching plans, interview notes, questionnaires, pictures and videos. The process of collaboration is sometimes equated with what is called voluntary change, which means the willingness to cooperate (Richardson 1998). The idea that teachers do not change and that they change all the time seems contradictory. Teachers resist change when change is initiated by others without their prior involvement. Voluntary change processes are attributable to teacher involvement. Teachers need to be encouraged to change as a collective rather than as individuals; that is, there should be collective reflection on teaching practice with the purpose of changing to what works best for them in their context.

Collaboration is characterised by a high level of teacher reflective processes. To manage change, teachers may work collaboratively with what is termed critical friends; that is, with colleagues who review the data critically and reflect on the teaching practice of their fellow-colleagues, thus sharing ideas (Mohr et al. 2004).

Reflection is usually employed to monitor the change process (Loreman et al. 2005). This is the process by which teachers reflect on their teaching practice in relation to the objectives they have set for themselves. Reflection could be done daily by the means of a reflection dairy, which is a record of every change that has been observed and experienced.

Reflective teaching and research will change teachers' perceptions of themselves and encourage them to try new ideas, methods and approaches (Nind \& Sheehy 2004). This collaborative reflection process is known as "mutual adaptation" because all who participate in the reflection process are bound to gain new ideas and therefore change (Richardson 1998). The process is on-going and teachers could engage in it throughout the day. In the course of reflecting, the following conceptual views of steps are considered (Hargreaves \& Fullan 2000):

- Experiment with teaching.

- Identify what works better in the class.

- Change perceptions of teaching.

The reflection process described above is sometimes associated with the notion of the teacher as a learner, which indicates that, through the reflective process, teachers are engaged in the process of learning about their own practices. The reflection process is also likened to what is called images of teaching and learning that teachers construct. Briscoe (1996: 47) defines this concept as "the knowledge that teachers have about their work and their role is constructed as sensory experiences and is given meaning through reflection". This process is dominated by the process of brainstorming or meaning-making which is important for teachers to learn from one another. 
The quality and effectiveness of change is something complex to measure; indeed, there is a belief that change cannot be managed (Fullan 2001). However, some authors argue that it can be managed and that change should be closely monitored (managed) by means of checklists (McCallion 1998).

Because change is viewed as a collective rather than as an individual process, it is necessary to explore how teachers make connections leading to the formation of collaborative groups. The concept of communities of enquiry is relevant in this context.

Collaboration is a process whereby teachers through collegiality, interaction and effective communication develop relationships which are mutual in reflecting on their practice and assisting one another to improve their practice. The most powerful aspect of teacher change is embedded in what is called a professional learning community (Fullan 2001). The development of a culture of collaboration enables teachers to work together; to develop confidence, a high level of motivation and positive self-efficacy, and the ability to influence the work of the learners positively. Teachers change as a result of motivation and collaboration (Save the Children 2002: 52).

Collaboration among teachers leads to what is known as a community of enquiry (Reason \& Bradbury 2006). This is a process where individuals become participants in a collective community to enquire about their practice. Through this reflective process, meanings are negotiated as they are usually informed by their historic cultural context. The development of such a community depends to a larger extent on processes of communication, meaning making and meaningful interaction between members of the community. The process of collaboration becomes pivotal in the communicative culture of the community and results in the culture of practice.

The notion of communities of enquiry is crucial to the implementation of educational reform in that it offers teachers the opportunity for growth and development (Hargreaves 1997). The notion of critical friends (viewing one another's work critically with a purpose of improving practice) is the basis on which teachers build connections as they engage in reflection and meaning-making (McTaggart 1997). The community of enquiry is also referred to as a learning community in the sense that the members are involved in a collective learning process which depends to a large extent on how well they interact, share meaning and collaborate with one another (Nind \& Sheehy 2004).

Therefore the development of an inclusive learning community as a process through which teachers develop an inclusive learning culture through collaboration and cooperation is crucial (Engelbrecht \& Green 2001). The theoretical framework for developing collaboration is based on the notion of a historic cultural approach and the belief that peer interaction is fundamental as a mediation tool (Cesar \& Santos 2006). Learning is viewed as a communicative process through which those involved in the learning process negotiate meaning, construct knowledge and allow the process of meaning exchange to shape their identity. The relationship between members in a community of practice is a symbiotic one in that members learn from one another. In this study Collaborative Action Research (CAR) was used as a data generating framework.

\section{Methodology}

In the first instance, CAR has been adopted in this study as a change strategy and is therefore imperative to discuss. The purpose of action research is to bring about change and empower the individuals or groups perceived to be disempowered or oppressed (O'Hanlon 2003). The purpose of the action research on which this study is based was to empower teachers and bring about change with regard to the inclusive teaching processes in their classrooms. This view is consistent with that of Dyson et al. (2012), who contend that inclusive practices should be developed as close as possible to local communities. This then leads to how teachers in communities conceptualise and understand different ways in which the process of change is the initiated and monitored. It is consequently important to place the notion of educational change in perspective within the framework of this action-research project.

\subsection{Implementing change through Collaborative Action Research}

CAR has the potential to work well as a change mechanism; for example, Somekh (in Altrichter \& Elliott 2003) postulates the theory of the changing nature of action research by drawing on her experiences. She defines collaborative action research as a vehicle for managing changes in the classroom and, therefore, a medium through which change can be implemented. Similarly, Mohr et al (2004) view CAR as a change strategy led by teachers and argue that teacher collaboration is important during the research process. Somekh (2006) concurs that collaborative action research is a methodology for change in schools. Change results from a process through which teachers embark on partnership, reflection and recognition of the ethical sensitivity of the research investigation process. Change is enhanced through good human relationships, effective communication and active participation (Stringer 2008). The research process was a 
four-stage collaborative action-research study and consisted of the following stages: planning, observation, action and reflection. Where deemed necessary, a stage was subdivided into phases. The table below gives a structural outline of each of the stages, followed by a brief summary of what happened during each stage (phase):

Table 1: Collaborative Action Research Stages and Phases

\begin{tabular}{|l|l|l|}
\hline \multicolumn{1}{|c|}{ Stage } & Phases & \multicolumn{1}{c|}{ Action } \\
\hline Stage1Planning & $\begin{array}{l}\text { Phase 1 } \\
\text { Phase 2 }\end{array}$ & $\begin{array}{l}\text { Preparation } \\
\text { Identification (brainstorming) }\end{array}$ \\
\hline Stage :Observation & Phase1 & $\begin{array}{l}\text { Observation of current practice } \\
\text { Focus-group interviews with learners } \\
\text { Participant observation on how inclusive practices } \\
\text { were used }\end{array}$ \\
\hline Stage 3:Action & Phase 1 & $\begin{array}{l}\text { Adopting practices in the class to develop teachers' } \\
\text { skills in using them to enhance full inclusion }\end{array}$ \\
\hline Stage 4: Reflection & $\begin{array}{l}\text { Phase 1 } \\
\text { Phase 2 }\end{array}$ & $\begin{array}{l}\text { Evaluating action research as a methodology } \\
\text { Writing a report and making recommendations }\end{array}$ \\
\hline
\end{tabular}

The initial preparation began firstly by obtaining permission from the Free State Education Department to carry out the research project, which included writing an official letter to request such permission. Once the permission was granted, I then asked for the volunteers among the teachers to establish the research task team for the project. To compensate for the major disadvantage of action research, which is the lack of research skills of the volunteer researchers, I conducted a one-day mini-workshop to familiarise the research task team with their roles and duties. To minimise my influence on the process as principal of the school (at the time), I jointly drew up a duty list with the teachers to explain how the meetings would be conducted, who would chair them, who would take minutes, and how decisions would be taken.

We convened meetings to brainstorm the concepts inclusive education, inclusive teaching and inclusive class in order to establish a common understanding of what they meant in our context and to determine how inclusive we thought our teaching was. The discussion questions were the following:

I. What do we understand by inclusive education, inclusive teaching and inclusive class?

II. How inclusive do we think our teaching has been?

Teachers were allowed to engage in an open discussion for them to air their views. At the request of the teachers, I presented some literature on inclusive practices so that we could compare or understanding and that in the literature.

To elucidate the notion of inclusion from the perspective of learners, I held an open focus group interview session with the (RCL) Learner Representative Council (a body of 20 democratically elected committee by learners and which was representative of all grades at school to look at matters of learner interest) to discuss questions such as the following:

I. Do you think all learners are catered for by the teaching in your classrooms?

II. Which activities and teacher practices in your opinion help you to learn effectively or fully take part in the class?

III. What would you like changed for you to be academically well-catered for in your classes?

Observations were used on two accounts: firstly, to determine how inclusive our current practice was and, secondly, during the action stage when practices were adopted in the class to develop their inclusive application in our school context. During the first phase of observations, we made notes mainly from memory. The observations were systematised by the use of a pre-planned observation schedule which addressed the research questions. Teachers suggested that it would be appropriate to keep daily reflection diaries. Observations in classrooms were integrated into the school routine, a move which was aimed at minimising disruptions of normal teaching periods. The following topics (as determined by us) guided the observations in relation to inclusion:

I. Curriculum-related aspects of the class (planning, presentation and assessment of lesson, interaction, participation, and seating arrangements during the lesson).

II. Teaching (pedagogic) aspects of the class (teaching approach and strategies, maintenance of discipline and motivation, the role of assistant teachers and the use of technology in the class).

III. Learning aspects of the class (use of learning approaches, e.g. cooperative learning, group work, peer tutoring and collaborative problem solving).

IV. Social aspects of the class (communication, diversity, relationships and values in the class). 
During the second phase of observations, we first agreed on the criteria for inclusion, then paired with one another according to curriculum relevancy, and did observations for six months.

Once the observations had been done, in-depth interviews were conducted with teachers to reflect on what had been observed and to gather more data on themes that might have emerged from the observations. Interview schedules with open-ended questions were used. Open-ended questions allowed the teachers to recount and reflect on their practices and broadly agree on the meaning of effective classroom teaching practices that promoted inclusion in their context.

Having identified and agreed on classroom practices that were regarded as effective in promoting inclusion, I collaborated with the research task team to draw up an action plan. The action plan was a detailed implementation programme to adopt effective classroom practices identified in the classes and evaluate how they promoted inclusive teaching and learning. The following were the proposed indicators of the classroom teaching practices that were effective; however, the proposed indicators were negotiated with the teachers themselves. I only offered guidance in this regard (adapted from the Index of Inclusion, Ainscow \& Booth 2002):

I. High level of participation of all learners, interaction and effective communication between all learners and the teacher, and cooperation among all learners.

II. High level of inclusive and differentiated instruction (catering for all learner needs), an atmosphere that fostered a high level of good human relations, and a high level of discipline in the class.

III. High level of tolerance of diversity, motivation of all learners, and achievement of expected outcomes by all learners.

During the action phase in the classrooms, the teachers were expected to record their experiences in the daily reflection diary. At the end of the action phase, I conducted follow-up interviews with open questions with teachers to evaluate the effectiveness of teaching practices that we had implemented in our classes over a given period. Reflecting on practice is very rarely practised by teachers in South Africa. Group interpretive processes were used by the volunteer research team and me to analyse and interpret the data.

A summary of conclusions and findings were drafted together with the research task team during this phase. The following questions were asked in an attempt to build a local theory: What was our understanding of inclusive education, inclusive teaching and inclusive class? What did the literature say about the concepts and how inclusive did we think our teaching was? What was the research telling us? What have we learned from the project?

While my role was to be part of the research team as an equal partner, I however had to provide purpose and direction to the study for it to start because teachers were conducting this kind of research for the first time. At the start, I dealt with ethical issues. During the first stage of our research, the teachers requested that I give them a presentation on the current research literature on inclusion. While I thought it would be easy for teachers to engage freely about their practices during our discussions, that was not the case. From time to time, I had to initiate the discussions. As requested by the teachers, I kept records of our proceedings and allowed the teachers access to them whenever it was needed. The objective of being critical in this study was to challenge power and hierarchical issues in curriculum delivery and decisionmaking; however, the contradiction was that I being the principal and arguably the most qualified teacher among the teachers posed a serious challenge as they regarded me as an authority figure. While the teachers in their reflections acknowledged that the process had been one of challenging power in terms of their role in taking decisions about their practice, the extent to which my status had an impact on their freedom to do this cannot be underestimated.

\subsection{Data analysis}

The data analysis took place at two levels, namely during collaborative action research through group interpretive process, and for the meta-research process. The data were collected, processed and analysed systematically. Data analysis means that, after collection, the data must be processed and meaning must be attached to it. It is therefore critical to look at different ways in which data are qualitatively analysed. The data-analysis process is always preceded by data-management processes as large quantities of data could be generated by means of qualitative research.

I must indicate that the two processes did not run parallel to each other but were interactive. In practice, the group interpretative analysis would take place at the level of engagements with teachers, but I went beyond and embarked on a meta-analysis, using an inductive analysis from a theoretical perspective. Group interpretative meetings were held after each phase. The meetings took the form of a discussion and the minutes of all the meetings were taken by me as the secretary of the volunteer research committee and afterwards verified by all the other members to check if they were a true reflection of the deliberations. The interpretative discussions were chaired by an elected chair for the meeting. The discussions were facilitated by asking questions to stimulate discussions. The group firstly read the data, determined 
themes, assigned extracts (quotations) to the themes, and then derived interpretations. Agreements on interpretations were reached through consensus. The dissenting views were discussed at length and recorded as such.

\section{Discussion of Findings}

As indicated earlier in this paper, the research attempted to identify some commonly used strategies in the implementation of inclusion, and to draw some lessons from the collaborative action research. In terms of collaborative action research as a medium of change, the following themes emerged: planning action research, action research as a strategy for change, action research and data collection, and action research and teacher collaboration.

\subsection{Theme: Planning a collaborative action-research study}

Planning a collaborative action-research study involved the following aspects

\subsubsection{Flexibility}

The analysis of the planning of the collaborative action-research process suggested that the plan might not necessarily evolve unchanged during the actual process. Indications were that the planning of collaborative action research had to be flexible and adaptable so as not to derail the process. For example, when faced with the problem of teachers not being willing to talk during our discussions, as a complementary measure I had to give them a questionnaire in order to obtain their views on the essential issues.

\subsubsection{Participation}

The analysis indicated that sustaining the participation of the research members and safeguarding the research effort was an on-going challenge. For instance, the number of participants declined from 21 to 15 at the start and subsequently declined even further during the research process. As the researcher, I therefore had to create mechanisms to keep the participants motivated and to sustain a credible number of participants for the project. For example, one of the teachers remarked: I am overloaded with marking work; sometimes it was difficult to attend all [the] meetings.

The analyses of the project participation showed that I had to take the following into consideration in order to mitigate the effect of the aforementioned issues:

I. The workload of participants: for example, the participants were willing to be part of the project if I performed some tasks such as writing minutes and keeping records;

II. The participants' ability to conduct research: the participants were willing to take part after I had given them training in research methods and the process involved in order to encourage participation in the project.

\subsection{Time to conduct a collaborative action-research project}

The analysis of the time spent on the project showed that the amount of time planned was different from the actual time spent on the project, as the following quotation suggests: I think the time we got was short for me and the learners to adjust fully to the newly introduced way of teaching and learning.

The planning and dates had to be adjusted continually to accommodate the professional commitments of the teachers. For example, at times there were several apologies for being unable to attend the meetings and research. It once again follows that the ability to be flexible is crucial in planning an action-research project. The success of collaborative action research depends on the participation of practitioners and the available time at the research group's disposal.

\subsection{Theme: collaborative action research as a strategy for change}

The process of collaborative action research was used in trying to change how teachers planned and acted in relation to being inclusive in their teaching. The analyses revealed several significant aspects. For example, it was evident that the project demonstrated that collaborative action research had created a platform for teachers to explore alternative ways of doing things, as one of the teachers stated: I have discovered that there could be alternative ways of doing things.

However, there was an indication that change as envisaged within this project might not have been achieved as it 
should have been, hence the following remark by one teacher: I think the time we got was short for me and the learners to adjust fully to the newly introduced way of teaching and learning.

In general, the project might have challenged the teachers' beliefs and attitudes about how they thought about their practices, as suggested by the following statement made by one teacher: I had an opportunity to start a new way of teaching successfully.

However, there is reason to believe that change, as it took place during the project, might not be sustainable. For instance, when asked about what was going to happen after the project, one teacher was pessimistic and said: I think we can do this all over again if our work load could allow it.

While collaborative action research may enhance change, the interpretation of the analysis suggested that it needed time and that mechanisms to sustain the process of change were necessary for change to be realised fully.

\subsection{Theme: collaborative action research and my role as the researcher}

One of the important aspects of collaborative action research is that the researcher becomes part of the research group. While it is not permissible within this mode of research for the researcher to impose his or her ideas on the research group, during this study, given South African teachers' culture of not taking any initiative, it was very tempting to flout this ground rule. For example, teachers requested me to take the lead in initiating some of the research activities, such as discussions, reflective engagements and sharing knowledge on some literature topics.

To some extent, the role of the researcher within a collaborative action-research mode seems to be determined by the context within which the study is conduced, the type of practitioners involved, their research skills, as well as their ability to initiate change, being critical, reflective and motivated. For example, during this project one could not but notice that the teachers regarded the researcher as an 'authority' and as a 'knowledgeable other'.

\subsection{Theme: collaborative action research and teacher collaboration}

One of the cornerstones of collaborative action research is its ability to foster collaboration among the practitioners. The analysis of this project clearly proves that when teachers work together they stand to benefit from one another. For example, in acknowledging this, one teacher praised action research for benefitting them through collaboration with others: I have learned to listen and share ideas with my colleagues.

While it was evident that the teachers had benefited from the process of collaboration, the analyses suggest that that collaboration needs time for its value to be fully realised. This became evident when one teacher lamented: I could learn a lot from colleagues but I think we should have done it more frequently. The interpretation is that the culture of collaboration does not happen overnight and that time is needed for its full realisation.

\section{Discussion}

The study has confirmed the CAR as a change strategy needs flexibility as the reality during the research field might dictate otherwise (Ainscow, Booth \& Dyson 2006). There is evidence to suggest that to use CAR as a strategy for change has far reaching implications for participation (Makoelle 2012; 2013). The study has shown that different strategies are required to keep the participation of participants high during the project (Makoelle 2012). The study has also shown that CAR needs more time if it is to be successful as a change strategy. The study has demonstrated that CAR as a change strategy could impact positively on how teachers think about change, for instance in this study teacher beliefs and attitudes towards change was more positive and the process gave them space to initiate, collaborate and own the changes as a community (Mc Taggart 1997; Boekaerts \& Cascallar 2006; Mohr et al. 2004) Reason \& Bradbury 2006; Somekh 2006). It also improved on their ability to critique and reflect on their practice essential for change process (Nind \& Sheehy 2004: Ainscow et al. 2011). While the researcher within the CAR process is not expected to be dominant and prescriptive to the participants, this study has shown that such is dependent on the context and the type of participants involved in a change process. It was evident that CAR allows teachers to share their expertise and consequently the improvement of their practice (Stringer 2008).

\section{Recommendations}

Because collaboration has been found to be pivotal in probing practices; therefore, a platform needs to be created where practitioners can collaborate in reflecting on their practice. In this case, the current research suggests the development of 
inclusive practices by pointing out that, for change to happen, teachers will have to be given the space to initiate change by themselves, plan and drive its implementation.

With regard to developing inclusive practices and inclusive policies, the study recommends the use of CAR through the establishment and development research teams, as constituted in this study, and the manner in which these research teams could be used to enhance the development of inclusive practices.

Research teams must be composed of teachers. While it could be advantageous to have experts on the inclusive education research teams, it is recommended that these professional research teams should be run and controlled by teachers themselves. The role of experts should be to advise, not to play a leading role. Research teams should function in such a manner that teachers collaborate with and learn from one another. The following are the main steps for teachers to follow in pursuing the process of enquiry (conducting research):

- Establish a research team.

- Create a platform for brainstorming and for the establishment of meaning.

- Identify good practice through observation.

- Develop a programme to share good practices in the classroom.

- Engage in review and reflection practices in the classroom.

- Discuss feedback jointly and determine local theories.

- Establish collaborative teaching forums.

The research revealed that, while South African teachers believe that collaborative teaching could enhance inclusion, this was not the case in the classrooms. Teachers teach as individuals and never share the teaching platform with their peers. The collaborative teaching forums could enhance an exchange of good practice among teachers leading to the empowerment of all teachers.

\section{Conclusion}

This study has highlighted several issues with regard to collaborative action research as a strategy to develop inclusive practices. Collaborative action research can indeed assist the teachers in making their teaching more inclusive. However, during the collaborative action-research process several challenges were registered. The process posed challenges as far as participation was concerned. This unique situation in South Africa was further complicated by the entrenched culture of non-participation during the apartheid era. There was the problem of teachers' inability to reflect critically on themselves and their practice. For example, data from my research dairy indicate that one of the factors hindering the collaborative action-research process was the fact that teachers hardly disagreed with anything said or done by authority figures (a culture of being submissive). Consequently, it could be very difficult for anyone in a position of authority (in my case, as the researcher) to elicit an honest opinion from the teachers about anything, which could have jeopardised the trustworthiness of the research process. However, this study has laid the basis for the use of CAR as a change strategy for implementing inclusive education.

\section{References}

Ainscow, M. 1999. Understanding the development of inclusive schools. London: Routledge Falmer Ainscow, M. \& Booth, T. 2002. Index of inclusion. Bristol: Centre for Studies in Inclusive Education (CSIE).

Ainscow, M., Booth, T. \& Dyson, A. 2006. Improving schools, developing inclusion. London: Routledge.

Ainscow, M., Dyson A., Goldrick, S. \& West, M. 2011. Developing equitable education systems. London: Routledge Falmer.

Altrichter, H. \& Elliott, J. 2003. Images of educational change. Buckingham: Open University Press.

Boekhaerts, M. \& Cascalar, E. 2006. How far have we moved toward the integration of theory and practice in self-regulation? Educational Psychology Review, 18:199-210.

Briscoe, C. 1996. The teacher as learner: Interpretations from a case study of teacher change. Journal of Curriculum Studies, 28(3):315329.

Cesar, M. \& Santos, N. 2006. From exclusion to inclusion: Collaborative work contributions to more inclusive learning settings. European Journal of Psychology of Education, 21(3):333-346.

Department of Education. 2001. Education White Paper 6: Building an inclusive education and training and system. Pretoria: Government Printers.

Department of Education. 2005. Guidelines for inclusive learning programmes. Pretoria: Government Printers.

Dyson, A., Kerr, K., Raffo, C. \& Wigelsworth, M. 2012. Developing children's zones for England. London: Save the Children. 
Engelbrecht, P. \& Green, L. 2001. Promoting learner development: Preventing and working with barriers to learning. Pretoria: Van Schaik.

Fullan, M. 1999. Change forces: The sequel. London: Open University Press.

Fullan, M. 2001. The new meaning of educational change. Third edition. London: Routledge Falmer.

Fullan, M. 2004. Leading in a culture of change: Personal action guide and workbook. San Francisco, CA: Jossey-Bass.

Goodson, I.F. 2003. Professional knowledge, professional lives: Studies in education and change. Philadelphia, PA: Open University Press.

Haney, J.J., Lumpe, A.T., Czerniak, C.M. \& Egan, V. 2002. From beliefs to action: The beliefs and actions of teacher implementing change. Journal of Science Teacher Education, 13(3):171-187.

Hargreaves, A. \& Fullan, M. 2000. Mentoring in the new millennium. Theory and Practice, 39(1):50-56.

Hargreaves, R.E. 1997. Beyond educational reform: Bringing teachers back in Buckingham: Open University Press.

Hoban, G.F. 2002. Teacher learning for educational change: A systems thinking approach. Buckingham: Open University Press.

Loreman, T., Deppeler, J. \& Harvey, D. 2005. Inclusive education: A practical guide to supporting diversity in the classroom. London: Routledge Falmer.

Makoelle, T.M. 2012. Analysing the use of action research to develop practices of inclusion: A case of a South African school. Journal of Sociology and Social Anthropology, 3(2):83-91

Makoelle T M 2013. Inclusive pedagogy in context: A South African perspective: Saarbrücken: Lambert Academic Publishing.

Makoelle, T.M. 2012. Social communication and inclusive teaching practices: An action research case study. Communitas Special Issue, 17(1):199-225

Makoelle, T.M. 2012. The state of inclusive pedagogy in South Africa: A literature review. Journal of Sociology and Social Anthropology, 3(2):93-102.

McCallion, P. 1998. Achievement for all: Achieving excellence in schools. London: The Stationary Office.

McTaggart, R. 1997. Participatory action research. New York: State University of New York Press

Mittler, P. 2000. Working towards inclusive education: Social context. London: David Fulton.

Mohr, M.M., Roger, C., Sanford, B., Nicerino, M.A., Maclean, M.S. \& Clawson, S. 2004. Teacher research for better schools. New York: Teacher College Press.

Nind, M. \& Sheehy, K. 2004. Making it happen: Inclusive education, learning from each other. Milton Keynes: Open University Press.

O'Hanlon, C. 2003. Educational inclusion as action research: An interpretive discourse. Berkshire: Open University Press.

Reason, P. \& Bradbury, H. 2006. Handbook of action research. London: Sage.

Richards, J.C., Gallo, P.B. \& Renandya, W.A. 2001. Exploring teachers' beliefs and the process of change. PAC Journal, 1(1):41-48.

Richardson, V. 1998. How teachers change. Focus on Basics, 2(c):7-11.

Save the Children. 2002. Schools for all: Including disabled children in education. London: Save the Children

Somekh, B. 2006. Action research: A methodology for change and development. Maidenhead: Open University Press.

Stringer, E. 2008. Action research in education. Upper Saddle River, NJ: Pearson Merril Prentice Hall.

Weber, E. 2007. Globalization "global" development and teacher work: A research agenda. Review of Educational Research, 77(3):279309. 